\title{
Using box model to estimate the impact of air pollution from an industrial plant
}

\begin{abstract}
Today, air pollution in developing countries, has imposed a significant negative effects on public health and the environment. Box model is among the techniques that are used for modeling and predicting of air quality. Box model is widely used in modeling of air pollution. In this paper, after collecting the necessary information from analyzing the chimneys of an industrial plant located in south west of Iran, predictions of the pollution distribution of $\mathrm{CO}$ gas was analyzed by the air box model. The formula of box model was written by Excel 2013 Microsoft software in 20 zones and 14 hours, and by entering the information, three-dimensional graph height, time and zone were obtained. It should be noted that if the selected times and zones are divided into smaller intervals, the accuracy of the estimation of pollution concentration in this model increases. The results showed that by the stability of air and reduced the volume of element, the accuracy prediction increases and the pollution of the industrial plant goes to towards the city. Contamination concentration (CO) after passing through the first zone of the city gradually decreases to the boundary that the concentration will

be the same in all zones.
\end{abstract}

Volume 2 Issue 4 - 2017

\author{
MohammadjavadMehrani,' Mohammad \\ Filvantorkaman, ${ }^{2}$ Farshad Arab Markade ${ }^{3}$ \\ 'Department of Civil,Water and Environmental Engineering, \\ Shahid Beheshti University, Iran \\ ${ }^{2}$ Department of Engineering, Islamic Azad University, Iran \\ ${ }^{3}$ Department of Control and Automation Engineering, Shahid \\ Beheshti University, Iran
}

Correspondence: Mohammad Javad Mehrani, Department of Civil,Water and Environmental Engineering, Shahid Beheshti University, Tehran, Iran, Tel +989 I 3803722 I, Fax +9866478360, Emailmj.mehrani@gmail.com

Received: December 19,2016| Published: April 06, 2017

Keywords: air pollution, box model, chimneys, industrial plants

\section{Introduction}

Industrial processes associated with different products and various materials compounds, environmental pollutions caused by industrial activity, particularly in water and air is necessary. Box models of air pollution are used to determine a certain volume of pollution to calculate the average concentration of pollution in certain places and times which are divided into steady and non-steady states. In steadystate, concentration of pollution is constant and does not change with time while in non-steady state it changes and non-steady state is discussed in this article. In previous studies, air pollution problems have been investigated using various tools and methods. Chen et al. ${ }^{1}$ studied many developed countries and a few developing Asian countries. ${ }^{1}$ Noorpour et al. ${ }^{2}$ studied the air pollution caused by the cement industry. They studied AERMOD model and according to all data in the cement industry centered on the city of Abik was defined. ${ }^{2}$ Dally and Zanetti examined studied the use of comprehensive models of air quality in 2007. ${ }^{3}$ Lyons et al. ${ }^{4}$ studied the air pollution of a city in Sao Paulo, Brazil. They were able to gain a strong correlation between car kilometers and emissions of greenhouse gases through box model. ${ }^{4}$ Shang et al. ${ }^{5}$ studied the relationship between air pollution and mortality in the short-term periods. They stated that the cause of death is the existence of several contaminated gases. ${ }^{5}$ The effect of speed limits for vehicles was evaluated by Bell \& Russell ${ }^{6}$ in Barcelona metropolitan area. ${ }^{6}$ Kumar et al. ${ }^{7}$ investigated the mathematical programming method to predict air pollution in a region of India and the results showed that in creating $\mathrm{NO}_{\mathrm{x}}$ contamination, the shares of homes, industry and carsis $53 \%, 7 \%$ and $40 \%$, respectively. ${ }^{7}$ Carnevale et al. ${ }^{8}$ evaluated the numerical models predictions of pollutants concentration. They were able to achieve effective strategies to control and reduce pollution. ${ }^{8}$ Oketola \& Osibanjo ${ }^{9}$ in a study of the estimation of the pollution load in Lagos by the planning system of industrial pollution concluded that the estimated accumulated pollution load ratings (tons per year) among intermediaries (i.e. air, land and water), chemical and pharmaceutical sector had the highest pollutants. ${ }^{9}$ Garg ${ }^{10}$ studied the local air quality and stated that its reason is the increased industrial and environmental pollutions. ${ }^{10}$ Misra et al. ${ }^{11}$ using a meteorological preprocessor called AERMET to describe the atmospheric conditions in the planetary boundary layer and a land preprocessor called AERMAP used to describe the height of the land. ${ }^{11}$ The study of Capelli ${ }^{12} \&$ Tartakovsky $^{13}$ is also noticeable. In this paper, after collecting the necessary information from analyzing the chimneys of an industrial plant located in south west of Iran, predictions of the pollution distribution of $\mathrm{CO}$ gas was analyzed by the air box model. The formula of box model was written by Microsoft Excel software in 20 zones and 14 hours, and by entering the information, three-dimensional graph height, time and zone were obtained.

\section{Materials and methods}

For data collection, the data from an active company in the oil industry in southwest of Iran have been used. Testo350xl measuring instrument from Testo German Company was used and its calibration was done and EPA standard methods were used for the measurement. Surveillance method was conducted in this way that for measuring emissions gasses, the exact sampling location is selected so that it would be in accordance with the standards set by the Environmental Protection Agency (EPA1 Method).Then output flow rate and also the diameter of the chimneys determined. At this stage, three points on the chimney at intervals of $16.7,50,83.3$ of the whole diameter of the chimney is determined device's probe is fixed at each point and we wait to the measurement values are constant on the display. If in the mentioned stage the results are differed more than $10 \%$ from the average of all test data, the test should be repeated (PAST-TEST). Figure 1 shows the analysis of emissions from the industrial unit and Figure 2 shows a picture of how to analysis and measurement of pollutants from the chimneys. The studied city was divided with 
the length of each region equal to 1000 meters (L). According to the working time of the chimneys, the time for the distribution the plume was selected in 14 hours. Wind speed at a height of 10 meters above the ground $(\mathrm{U})$ is $1080 \mathrm{~m}$ per hour, temperature inversion height $(\mathrm{H})$ equal to 20meters and input $(\mathrm{Ci})$ and persistent $(\mathrm{C} 0)$ concentrations in the city are 5.4 and $10 \mathrm{mg}$ per cubic meter, respectively. The box model in which Formula (1) determines how to air pollution emissions from the chimney at a certain time on a certain range, is shown. ${ }^{14}$

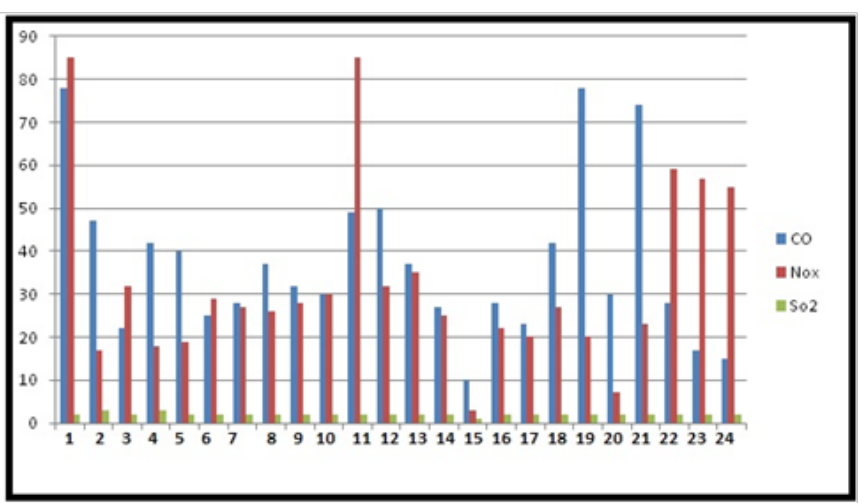

Figure I Analysis of emissions from the chimneys of industrial unit.
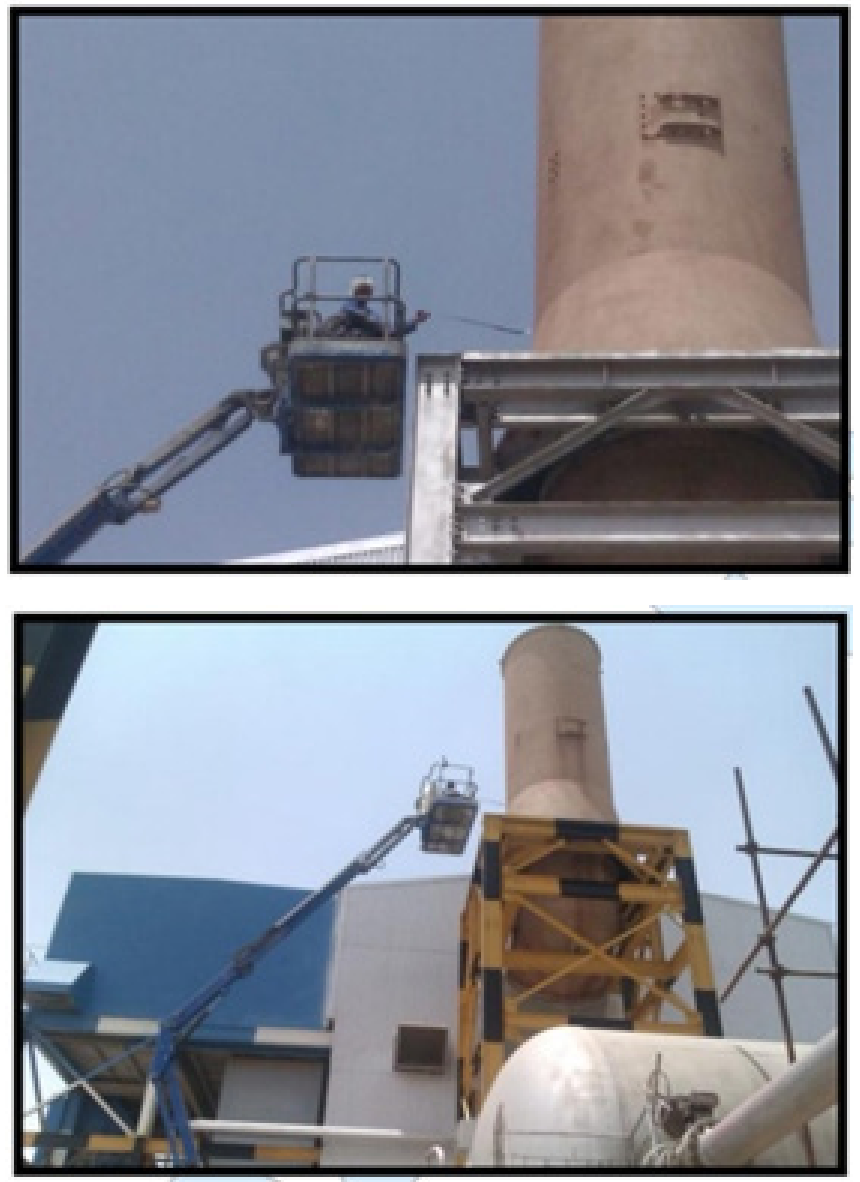

Figure 2 Analysis of exhaust gas.

$$
\frac{d c}{d t}=\frac{q}{H}+\frac{U}{L} \cdot C \cdot-\frac{U}{L} \cdot C
$$

$$
\begin{aligned}
& \frac{d c}{d t}=\frac{U}{L}\left(C_{o}-C_{i}\right)=\frac{q}{H} \\
& \frac{d c}{d t}+p y=Q \\
& C_{t}=\left(C_{i}+\frac{L \cdot q}{U \cdot H}\right)\left(1-e^{-\frac{U t}{L}}\right)+C(0) e^{-\frac{U T}{L}}
\end{aligned}
$$

Where, $\mathrm{L}, \mathrm{H}, \mathrm{W}$ are the length, height and width, $\mathrm{q}$ is mixing the air city, $U$ is the rate of emissions per unit area $(\mathrm{mg} / \mathrm{m} 2 . \mathrm{sec}), \mathrm{W}$ is the average velocity of air entering and exiting from the city, $\mathrm{C}_{\mathrm{i}}$ and $\mathrm{C}_{\mathrm{o}}$ are the concentration of entering and exiting air from the city. In general, it is necessary to correct the amounts of gases such as NO, $\mathrm{NO}_{2}, \mathrm{CO}, \mathrm{SO}_{2}$ due to the effects of excess air on their concentrations. ${ }^{15}$ The rate of excess air according to the amount of measured oxygen in the exhaust gases is determined. The measured Oxygen level along with a reference amount of oxygen is used to calculate the amount of the corrected gas in formula 2 .

The corrected $\mathrm{ppm}=$ the measured $\mathrm{ppm} \times \frac{\text { reference oxygen }-20.94}{\text { measured oxygen }-20.94}$

The selected city to study the impact of pollution on it was a town in the south of Iran with a total area of 423square kilometers and a length of $20 \mathrm{~km}$ in the direction of pollution propagation. The industrial plant that is active in the production of petroleum products is located on the West side of the city that pollution from the chimneys is towards the city and is sent along the wind direction. Figure 3 shows the location of industrial plant and the city.

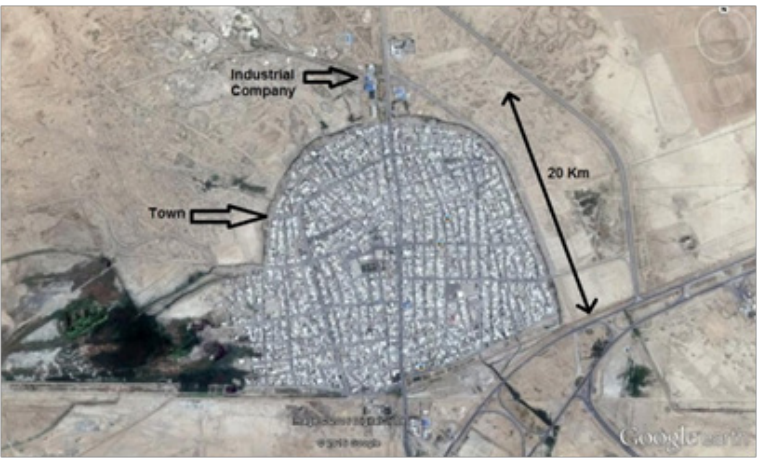

Figure 3 Aerial view of industrial plant positioning and the studied city in south of Iran.

\section{Analysis}

To increase the accuracy of calculations, the city should be divided into smaller elements and each element should be examined at any time to obtain the emission of the plume at every hour and in each area, and the progress of the plume is determined that finally the city was divided into 20 sections and were evaluated in 14 hours. The data from Figure 2 that are related to the concentration of $\mathrm{CO}(\mathrm{q})$ from the chimneys of the industrial units were entered in the programming formula of number 1 in the Excel 2013 software and for each area per hour were evaluated, and its results are presented in Table 1 and its three-dimensional graph is presented in Figure 4. 
Table I The results of chimney analysis in 14 hours and 20 zones of the city

\begin{tabular}{|c|c|c|c|c|c|c|c|c|c|c|c|c|c|c|c|}
\hline & & \multicolumn{14}{|c|}{ Time } \\
\hline & & I & 2 & 3 & 4 & 5 & 6 & 7 & 8 & 9 & 10 & II & 12 & 13 & 14 \\
\hline \multirow{20}{*}{ Zone } & I & 191 & 273.3 & 283.6 & 284 & 284 & 284 & 284 & 284 & 284 & 284 & 284 & 284 & 284 & 284 \\
\hline & 2 & 194 & 437.8 & 547.4 & 562 & 562.6 & 562.6 & 562.6 & 562.6 & 562.6 & 562.6 & 562.6 & 562.6 & 562.6 & 562.6 \\
\hline & 3 & 194 & 440.5 & 705.6 & 824.4 & 840.5 & 841.2 & 841.2 & 841.2 & 841.2 & 841.2 & 841.2 & 841.2 & 841.2 & 841.2 \\
\hline & 4 & 194 & 439.5 & 708.1 & 980.5 & 1102.5 & 1119.1 & 1119.8 & 1119.8 & 1119.8 & 1119.8 & 1119.8 & 1119.8 & 1119.8 & 1119.8 \\
\hline & 5 & 194 & 440.5 & 707.2 & 983 & 1257.9 & 1380.9 & | 397.7 & 1398.4 & 1398.5 & I 398.5 & 1398.5 & 1398.5 & 1398.5 & 1398.5 \\
\hline & 6 & 194 & 440.5 & 708.2 & 982.1 & 1260.4 & I536.| & 1659.5 & 1676.3 & I677.I & I677.I & I677.I & I677.I & I677.I & I677.| \\
\hline & 7 & 194 & 440.5 & 708.2 & 983.1 & 1259.5 & 1538.6 & 1814.6 & 1938 & 1954.9 & 1955.7 & 1955.7 & 1955.7 & 1955.7 & 1955.7 \\
\hline & 8 & 194 & 440.5 & 708.2 & 983.1 & 1260.4 & I537.7 & 1817 & 2093.I & 2216.7 & 2233.6 & 2234.3 & 2234.3 & 2234.3 & 2234.3 \\
\hline & 9 & 194 & 440.5 & 708.2 & 983.1 & 1260.4 & 1538.6 & 1816.1 & 2095.6 & 2371.7 & 2495.3 & $25 \mid 2.2$ & 2512.9 & 2512.9 & 2512.9 \\
\hline & 10 & 194 & 440.5 & 708.2 & 983.1 & 1260.4 & 1538.6 & $1817 . \mid$ & 2094.7 & 2374.2 & 2650.3 & 2773.9 & 2790.8 & 2791.5 & 2791.5 \\
\hline & II & 194 & 440.5 & 708.2 & 983.1 & 1260.4 & 1538.6 & $1817 . \mid$ & 2095.6 & 2374.2 & 2652.8 & 2928.9 & 3052.5 & 3052.5 & 3052.5 \\
\hline & 12 & 194 & 440.5 & 708.2 & 983.1 & 1260.4 & 1538.6 & $1817 . \mid$ & 2095.6 & 2374.2 & 2652.8 & 2931.4 & 3207.5 & 3207.5 & 3207.5 \\
\hline & 13 & 194 & 440.5 & 708.2 & 983.1 & 1260.4 & 1538.6 & $1817 . \mid$ & 2095.6 & 2374.2 & 2652.8 & 2931.4 & 3210 & 3210 & 3210 \\
\hline & 14 & 194 & 440.5 & 708.2 & 983.1 & 1260.4 & 1538.6 & $1817 . \mid$ & 2095.6 & 2374.2 & 2652.8 & 2931.5 & 3210 & 3210 & 3210 \\
\hline & 15 & 194 & 440.5 & 708.2 & 983.1 & 1260.4 & 1538.6 & 1817.1 & 2095.6 & 2374.2 & 2652.8 & 2931.5 & 3210.1 & 3210.1 & 3210.1 \\
\hline & 16 & 194 & 440.5 & 708.2 & 983.1 & 1260.4 & 1538.6 & $1817 . \mid$ & 2095.6 & 2374.2 & 2652.8 & 2931.5 & 3210.1 & 3210.1 & 3210.1 \\
\hline & 17 & 194 & 440.5 & 708.2 & 983.1 & 1260.4 & 1538.6 & $1817 . \mid$ & 2095.6 & 2374.2 & 2652.8 & 2931.5 & 3210.1 & 3210.1 & 3210.1 \\
\hline & 18 & 194 & 440.5 & 708.2 & 983.1 & 1260.4 & 1538.6 & $1817 . \mid$ & 2095.6 & 2374.2 & 2652.8 & 2931.5 & 3210.1 & 3210.1 & 3210.1 \\
\hline & 19 & 194 & 440.5 & 708.2 & 983.1 & 1260.4 & 1538.6 & $1817 . \mid$ & 2095.6 & 2374.2 & 2652.8 & 2931.5 & 3210.1 & 3210.1 & 3210.1 \\
\hline & 20 & 194 & 440.5 & 708.2 & 983.1 & 1260.4 & 1538.6 & 1817.1 & 2095.6 & 2374.2 & 2652.8 & 2931.5 & 3210.1 & 3210.1 & 3210.1 \\
\hline
\end{tabular}

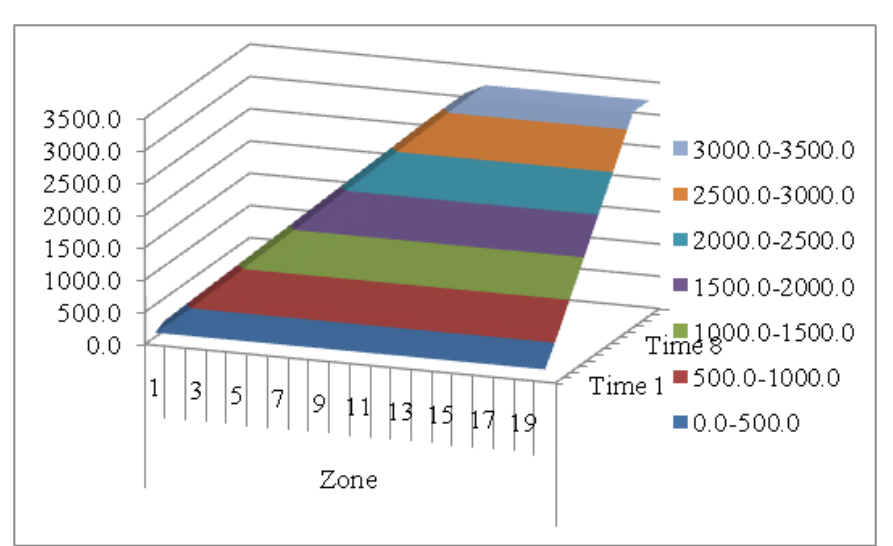

Figure 4 Three-dimensional graph of the concentration of $\mathrm{CO}$ in each zone, time and height.

\section{Conclusion}

Air pollution has become one of the most important problems of the world's metropolises. Industrial cities because of their proximity to several factories and refineries are very exposed to air pollution. As the smoke from the factories causing air pollution, many factories by creating tall chimneys could reduce air pollution around the chimney. However, these chimneys reduced the severity of pollution in the surrounding area; it also expanded the size of the contaminated environment. Air box model to predict and quantify the impact of air pollution concentration of $\mathrm{CO}$ in the nearby town was examined it. In the non-steady state, the concentration is not constant at all points and changes with time. According to Figure 4, with stability of the air and reducing the volume of element, the accuracy of the prediction increased and the pollution of the industrial plant was sent towards the city. Pollution concentrations (CO) after passing through the zone 13 of the city, was gradually fixed until the border that the concentration was the same in all zones. The smaller the selected zones and time periods, the accuracy of the estimation of pollution concentration increases in this model.

\section{Acknowledgements}

None.

\section{Conflict of interest}

The author declares no conflict of interest.

\section{References}

1. Chen R, Pan G, Kan H, et al. Ambient air pollution and daily mortality in Anshan, China: a time-stratified case-crossover analysis. Science of the total environment. 2010;408(24):6086-6091.

2. Noorpoor A, Rahman HR. Application of AERMOD to local scale diffusion and dispersion modeling of air pollutants from cement factory stacks (Case study: Abyek Cement Factory). Pollution. 2015;1(4):417426. 
3. Daly, A, Zannetti P. Air pollution modeling-An overview. Ambient air pollution. Published by The Arab School for Science and Technology; 2007;27:1-14.

4. Lyons TJ.An international urban air pollution model for the transportation sector. Transportation Research Part D: Transport and Environment. 2003;8(3):159-167.

5. Shang Y, Sun Z, Cao J, et al. Systematic review of Chinese studies of short-term exposure to air pollution and daily mortality. Environ Int. 2013;54:100-111.

6. Bel G, Rosell J. Effects of the $80 \mathrm{~km} / \mathrm{h}$ and variable speed limits on air pollution in the metropolitan area of Barcelona. Transp Res Part D Transp Environ. 2013;23:90-97.

7. Sivacoumar R. Air pollution modeling for an industrial complex and model performance evaluation. Environ Pollut. 2001;111(3):471-477.

8. Carnevale C, Finzi G, Pisoni E, et al. The impact of thermodynamic module in the CTM performances. Atmospheric environment. 2012;61:652-660.

9. Oketola AA, Osibanjo O. Estimating sectoral pollution load in Lagos by Industrial Pollution Projection System (IPPS). Sci Total Environ. 2007;377(2-3):125-141
10. Garg A. Pro-Equity Effects of Ancillary Benefits of Climate Change Policies: A Case Study of Human Health Impacts of Outdoor Air Pollution in New Delhi. World Development. 2001;39(6):1002-1025.

11. Misra A, Roorda MJ, MacLean HL. An Integrated Modelling Approach to Estimate Urban Traffic Emissions. Atmospheric Environment. 2013;73:81-91.

12. Capelli L, Sironi S, Del Rosso R, et al. Measuring odours in the environment vs. dispersion modelling: A review. Atmospheric Environment. 2013;79:731-743.

13. Tartakovsky D, Broday DM, Stern E. Evaluation of AERMOD and CALPUFF for predicting ambient concentrations of total suspended particulate matter (TSP) emissions from a quarry in complex terrain. Environ Pollut. 2013;179:138-145.

14. Henry C Perkins. Air pollution. USA: McGraw-Hill; 1974. 156 p.

15. Shiva Nagendra SM, Diya M, Chithra VS, et al. Characteristics of air pollutants at near and far field regions of a national highway located at an industrial complex. Transportation Research Part D: Transport and Environment. 2016;48:1-13. 